BIJ

20,4

512

Received 17 August 2011

Revised 9 December 2011

Accepted 9 December 2011

\section{Performance evaluation of e-government services using balanced scorecard}

\section{An empirical study in Jordan}

\author{
Salah Alhyari \\ School of Business and Finance, \\ The World Islamic Sciences \& Education University, Amman, Jordan \\ Moutaz Alazab \\ School of Information Technology, Deakin University, Burwood, Australia \\ Sitalakshmi Venkatraman \\ Department of Higher Education, Victorian Institute of Technology, \\ Melbourne, Australia \\ Mamoun Alazab \\ Regulatory Institutions Network, Australian National University, \\ Canberra, Australia, and \\ Ammar Alazab \\ School of Information Technology, Deakin University, \\ Burwood, Australia
}

\begin{abstract}
Purpose - The purpose of this paper is to emphasise on a balance between quantitative and qualitative measures, and examine the use of Balanced Scorecard to evaluate and estimate the performance of information and communication technologies (ICT) in delivering valuable e-government services through the internet.

Design/methodology/approach - This study tests the hypotheses of e-government effectiveness using Balanced Scorecard technique by incorporating qualitative measures within a quantitative research methodology with data collected by means of a survey questionnaire. The survey sample of 383 stakeholders includes common customers, employees of e-government, and employees from the IT sector. The survey data were analysed to test the hypothesis in measuring e-government effectiveness from Balanced Scorecard's four dimensions: customer perspective, financial perspective, internal business process perspective, and innovation and learning perspective.

Findings - The results show that the Balanced Scorecard factors fit very well with monitoring and measuring the performance of e-government in Jordan, and also in evaluating their success in IT project investments.

Originality/value - This study attempts to address this gap in the literature and would benefit future studies in applying Balanced Scorecard for performance evaluation of various IT projects that are gaining huge investments from governments and organisations.
\end{abstract}

Keywords E-government, Balanced scorecard, Performance management systems, Jordan, Developing countries, E-government performance evaluation, Performance measurement system

Paper type Research paper
Benchmarking: An International Journal

Vol. 20 No. 4,2013

pp. $512-536$

(c) Emerald Group Publishing Limited 1463-5771

DOI 10.1108/BI-08-2011-0063 


\section{Introduction}

Governments should respond to the changes in different innovative mechanisms and continuous improvements that are warranted in the world today. Performance measurement mechanisms have evolved with dynamic changes that have led governments to search for new ways to measure the return on investment to maximize stockholder wealth, and at the same time to measure their performance in engaging customers (citizens) to support e-government (UN Report, 2006; Castelnovo and Simonetta, 2007; Ying, 2010).

The launch of the e-government project in Jordan at the end of the year 2006 has recently included the provision of e-government services in a number of departments and various government institutions to address the needs of various sectors, including citizens, business, and the government, most of the organizations in public sector are not aware of the importance of performance measurements, in terms of how they could be employed for organizational and systems measurements in reviewing budget items and expenses, and also to measure the return on investment. Reinventing government trend recommends that public organizations should be more mission-driven, customer-focused, result-oriented, and decentralized to meet the needs of citizens or clients (Ellingson and Wambsganss, 2001).

The concept of e-government is complex and covers fields, which differ a lot from each other. This heterogeneity can be a problem in the definition of a model for the evaluation of the impact that e-government projects can have (Castelnovo and Simonetta, 2007). Electronic government is no longer just an option but a necessity for countries aiming for better governance (Gupta and Jana, 2003). Many governmental units across the world have embraced the digital revolution and placed a wide range of materials on the web, from publications to databases to actual government services online for the use of citizens (Srinivasan and Iyappan, 2009).

Evaluation is generally regarded from one of two perspectives. In the ex ante perspective, candidate systems or technologies are evaluated before they are chosen and acquired or implemented. In the expost perspective, a chosen system or technology is evaluated after it is acquired or implemented (Klecun and Cornford, 2005) and is also regarded from process evaluation context (Kaplan, 2010).

Conducting e-government evaluation would lead to monitoring changes in e-government environment and also to assess the efficiency of implementing e-government program in order to improve the procedure of service delivery. Evaluation of e-government efforts is sought by management to provide strategic guidance for the government organizations (Gupta and Jana, 2003). E-government evaluation refers to assessing and examining the activities to understand the process and result of e-government programs, and it has two types: e-government achievement level (current state) and e-government program evaluation.

Applying performance measures is essential to evaluate whether e-government is cost efficient, is serving stakeholders, and is being used effectively by government agencies, staff, citizens, and businesses (Fountain, 2001). Agencies can use various quantitative and qualitative output measures to evaluate their e-government programs, including the number of hits on a site, user contact sessions, number of downloads, amount of time spent on site, information accessed most frequently, and number of times forms are completed (Stowers, 2004). There are many performance measures including Balanced Scorecard (BSC) reported in literature (Gunasekaran and Kobu, 2007;
Evaluation of

e-government services

513 
BIJ

20,4

514
Werner and $\mathrm{Xu}, 2011)$. BSC could provide an objective benchmarking indicator for evaluating the achievement of the strategic goals of an organisation (Punniyamoorthy and Murali, 2008). However, there is a lack of literature reporting on its application in e-government performance evaluation.

In this paper, we examine the BSC as a technique to evaluate and estimate the performance of Jordan E-government. The empirical study to test the effectiveness of e-government using BSC is conducted by analyzing the survey data obtained from a sample of 383 stakeholders that includes common customers, employees of e-government, and employees from IT sector. This paper demonstrates the application of BSC framework to evaluate performance of e-government services in Jordan and the insights gained will contribute towards further research in developing new approaches to performance measurement and evaluation (Gunasekaran and Kobu, 2007).

This paper is organized as follows. Second section describes performance measurement systems found in literature, and third section gives background work done in e-government performance evaluation. The BSC theory is provided in fourth section and in fifth section, the research model and hypotheses used to apply BSC approach to evaluate Jordan's e-government services are presented. Sixth section discusses the results and findings, and seventh section presents the conclusion of this paper.

\section{Theoretical foundation}

Performance measurement systems

Definitions. Performance measurement system can be defined as the set of metrics used to quantify both the efficiency and effectiveness of actions (Neely et al., 1996a, b). Also, performance measurement refers to the use of a multi-dimensional set of performance measures that includes both financial and non-financial measures, it includes both internal and external measures of performance and it often includes both measures which quantify what has been achieved as well as measures which are used to help predict the future (Neely, 1998). The purpose of performance measurement system is to ensure that standards and objectives are set clearly, that performance is regularly and objectively assessed for accomplishments, and that actions are taken to improve and enhance performance potential in the future (Ababneh, 2008).

In this paper, we define performance measurement system as the processes developed by organization to asses, estimate and measure performance of organization in using its resources and its investments to enable organizations to perform better and improve their performance. A good performance measurement system should be able to provide to all stockholders where they are, how the organization is doing, and where the organization is going.

\section{Performance measurement models}

Performance measurement has its roots in early accounting systems (Johnson, 1981), and many traditional measurement and evaluation methods such as return on investment (ROI), economic value added (EVA), net present value (NPV), internal rate of return (IRR), return on capital employed (ROCE), have failed to yield an appropriate estimate of the "pay back" from these complex systems (Sedera et al., 2001). The reason for this problem is that firms have many systems to operate and have many stockholders' interest such as government, unions, and also consumers and other agencies. However, the main concern to serve consumers' needs has focused attention on the effectiveness in measurement performance. 
A growing number of companies have begun searching for new ways to measure the return on investment from their IT projects, in particular emphasis on performance measures (Cameron and Whetten, 1983; Thorp, 1999; Kaplan, 2010). Performance measurement is a comprehensive measure, which is determined by collecting all the factors affecting the progress towards the target, and by measuring outcome. It should be comprehensive enough to accommodate even factors pertaining to social, personal, media and other intangible business aspects as well.

There are two popular models, according to literature review, that relate to performance measurement system, namely activity based management (ABM), and BSC that have built into the system the following main performance measurement design processes (Bourne et al., 2003):

- Putting the BSC to work. This is achieved by describing how an external customer view was introduced into the scorecard development process (Kaplan, 1994). This process helps to get new customer perspective and allow the company to segment its market and to develop strategies, actions and measures that underpin the development of its chosen niche or specific segment.

- The performance model. The processes for creating a business performance model involve facilitating the senior management team through a review of their business strategy by determining the objectives and the way to achieve those (Jeanes, 1996).

- Getting the measure of business. This process involves identifying groups of products or services, developing business objectives from customer and stakeholder needs, designing individual performance measures, reviewing the measures developed and providing advice on implementation and performance reviews (Neely et al., 1996a, b).

- The performance measurement questionnaire (PMQ). The approach of adopting a PMQ for evaluating and developing the measures for organizations is already in use (Dixon et al., 1990).

The implementation of a performance measurement system faces obstacles and barriers such that the vision and strategy become not actionable. This could occur when top management failed to translate organization vision into formulating strategies or the strategies were not linked to department, team and individual goals. In some cases, following the old traditional performance criteria could thwart the introduction of the new strategy or the new strategy was not linked to resource allocation or little time was reserved for the review of indicators of strategy implementation (Bourne et al., 2003). These issues should be taken into account while designing the performance measurement system and the questionnaire for evaluation.

To achieve the true purpose of performance measurement system, individual measures should be easy to understand, purposeful and cost effective. In addition, performance measurement system should be integrated over business functions and hierarchy of operations, should provide information for planning future performance, should reinforce the firm's strategies, and show the results as functions of determinates. More importantly, performance measurement system and environment should match with the firm's culture and provide data for external comparison and benchmarking (Neely et al., 1995).

\section{Evaluation of \\ e-government services}

515 
BIJ

20,4

516
E-government performance evaluation

Since 2001 e-government has been one of the main application domains for information and communications technology (ICT). Moreover, it represents a test bed - not just in Europe and in the USA, but worldwide (Castelnovo and Simonetta, 2007; Corradini et al., 2008; Ying, 2010). The emergence of e-government is witnessed due to the developments in ICTs that are harnessed to deliver the operations of government services (Alkhaleefah et al., 2010). The goals of e-government include facilitating service delivery, to promote responsiveness, equity, effectiveness and efficiency, accountability, transparency, the rule of law, openness and knowledge sharing (UN Report, 2006). E-government refers to the use of technology, especially internet applications based on networks of web sites to support and promote access to government information and delivery, serve the citizens and the business sector, employees and departments, other government efficiency and effectiveness (West, 2000). Also, it is defined as the totality of the information, services and products that is provided electronically by the government (Greunz et al., 2001).

After the initial investment and growth in e-government, all the governments are confronted with the question of how to evaluate e-government performance. Financial accounting measurements are extensively employed to evaluate government performance, but they do not indicate the reasons for those outcomes and how to improve them (Wright et al., 1999). Therefore, many lead governments are seeking for an appropriate performance measurement tool to evaluate and improve their e-government services.

Walsham (1999) and many researchers report that a well-documented and formal approach to investment evaluation is required to understand the implications of any ICT investment on the organization. Ying (2010) described the mainly problems facing e-government performance evaluation: first, focusing on technical indicator, and not much on governance indicators; second, bad measurement methods; third, weak management system of e-government performance evaluation. Also, the work has established that targeting on government web sites is the main way to evaluate e-government performance, as it boosts the government web site's construction, information openness, and service improvement. But some e-government performance evaluation focuses on outputs. Such as the number of clicks on the web sites, the number of services and the interaction with the public, instead of outcomes such as the utilization rate and customer satisfaction. Moreover, such work emphasizes on the result and not the process, and this discourages the participation from public managers as it gives incentives to them to address the results only.

The resulting problems are the unilateralism of evaluation and over-investment in government web site's construction without careful consideration and design. Based on these observations made, it is important for e-government evaluation to take all aspects that affect in improving and modernizing the overall performance of e-government. Also, when performance measures for customer, internal process and learning and innovation perspectives are added to the financial metrics, the result is not only gives a broader perspective on the company's health and activities, it is also a powerful organizing framework (Kaplan and Norton, 1996). While statistical based approaches such as Six Sigma and process-based approaches such as ISO9001 are also being attempted in many industries, BSC has been adopted for Jordan E-Government as it has the advantage of implementing and measuring the drivers for creating long-term shareholder value. Such a balanced performance measure is warranted in developing countries such as Jordan, since financial measurement models that are predominantly short-term measurement models may not lead to a successful adoption of e-government services by their citizens 
as well as employees (Yu et al., 2008; Werner and $\mathrm{Xu}$, 2011). Hence, this paper has investigated on the effect of applying BSC concepts as it also contributes towards increasing the understanding and knowledge of e-government evaluation.

\section{The Balanced Scorecard}

The BSC framework developed by Kaplan and Norton (1992) is based on their research conducted on different firms. The BSC has received a great deal of attention as a strategy that integrates financial and non-financial performance measures to help organizations in the learning and improvement of their internal and external processes (Ababneh, 2008). The BSC has gained a clear prominence among researchers as an approach of integrating financial and non-financial performance measures. Responsive organization should utilize the BSC as a tool to measure its performance health (Brown, 2007).

Horngren et al. (2000) have defined BSC as the way to convert or translate mission of firm and strategies into performance measurements, which means BSC allows the comparison of actual performance with planned performance. Jyoti and Deshmukh (2008) define BSC as a strategic measurement system including both non-financial and financial measures adopted to measure the performance of a business organization. Also Maiga and Jacobs (2003) argued that the BSC could be considered as a main tool in evaluating organizations comprehensively when dealing with highly changeable environment and as a response to the new global competition.

There are two features that distinguish the BSC from more traditional performance measurement system:

(1) the development of performance measures by translating mission, objectives and corresponding strategies of the organization; and

(2) linking together of the measurements under the perspectives (Yu et al., 2008).

Hence, in this paper, we have considered BSC as a multi-dimensional set of performance measures that not only includes both financial and non-financial measures but are related to four main dimensions or perspectives that are linked together such measures from financial perspective, customer perspective, internal business process, and innovation and learning perspective (Figure 1). According to Kaplan and Norton (1993), through the various BSC perspectives, vision of organization and strategy of business units could get translated into objectives and measures as shown in Figure 1.

Each perspective must consider and linking with the following items:

- strategic objectives (growth, profitability, customer satisfaction, process excellence);

- measures (revenue growth, return on equity, number of complaints, yield);

- targets; and

- initiatives.

Most measurement systems serve a narrow regulatory, clinical, or diagnostic function. They are not constructed to tell the story of organization strategy and guide the implementation (Inamdar et al., 2002) and other measurement systems do to timelines not offered. The importance of BSC is in the ability to portray the complexity relationship of the strategy.

\section{Evaluation of \\ e-government services}

517 
BIJ

20,4

\section{8}

Figure 1.

BSC perspectives

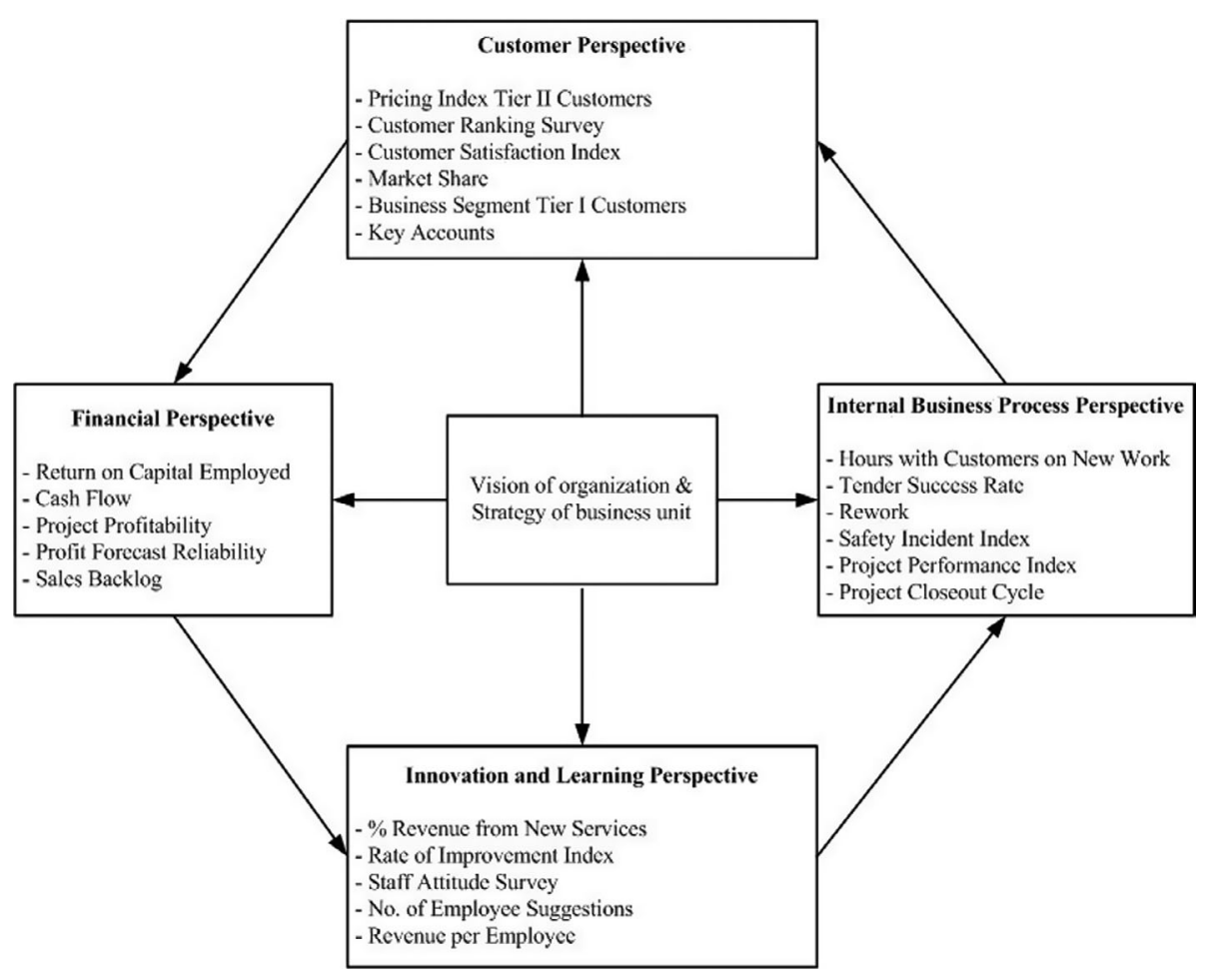

Source: Adapted from Kaplan and Norton (1993)

In customer perspective, performance must be measured throughout to match the needs of customers, create the demand for a new process or technology and provide value to the customer so as to improve customer satisfaction (Jyoti and Deshmukh, 2008). Also, it must consider evaluating how quick the response to customers' complements, complaints and satisfaction is. The major measurement for this perspective is the average and percent of customer complaints as well as the percent of employees who serve the customers. Items that could be easily measured are, number of customers profiled, number of customers with financial plans, number of targeted customer using online channel for transactions, and customer survey responses on questions related to appreciation and ease of working with the financial aspects (Kaplan, 2010). Customers as stockholder have interests in the firm based on previous measurements and will contribute to the firm in setting its strategies in order to succeed.

In internal business process perspective, top management of the firm determine the critical business processes that are related in activities, which achieve competitive advantage such as operation processes and innovation as well as fulfillment processes (Kaplan and Anthony, 1998; Kaplan and Norton, 1992). The main initiative for this perspective from customers is that the business processes are implemented towards delivering value to customers.

In financial perspective, as defined by Kaplan and Norton (1996) "the readily measurable economic consequences of actions already taken". This means, the rerun 
on investment, level of operation income, and cash flow measure the financial status of firm. It is also important to inform consumers how the firm is doing year after year and actions taken as a way of reflecting financial performance of organizations. Such factors closely related an organiation's production or service type could be used for evaluating the financial dimension of any organization.

In innovation and learning perspective, the focus is on measuring the investment in human resources, and the main measurements for this perspective are, expenditures of research and development and cost of training (Judeh, 2008). So in this perspective, determining firm infrastructure, such as used technology and the efficiency of systems will help in achieving firm goals and objectives. Evaluation of learning and growth dimensions should consider the employee performance and business innovation (Kaplan, 2010; Ying, 2010). Some of the learning and growth dimensions of evaluation indicators could be: the sustainable development ability, staff training, research and development investment and acquisition of information.

When adopting the BSC approach, top management team embraces a "vision for change" and nurtures a sense of team-spirit and collaboration. According to performance management experts (Rohm, 2002) the process is more "about changing hearts and minds and sustaining new directions, than it is about selecting performance measures".

\section{Research method}

This research study investigates the adoption of BSC that follows nine sequential processes or steps (Sharma, 2009) as shown in Figure 2.

Assessment of the organization's mission, vision, challenges and values: this refers to the situation that the organization seeks to achieve in the long-term (Niven, 2003). The organization's mission has the primary purpose of providing justification and reason for organization existence and continuity.
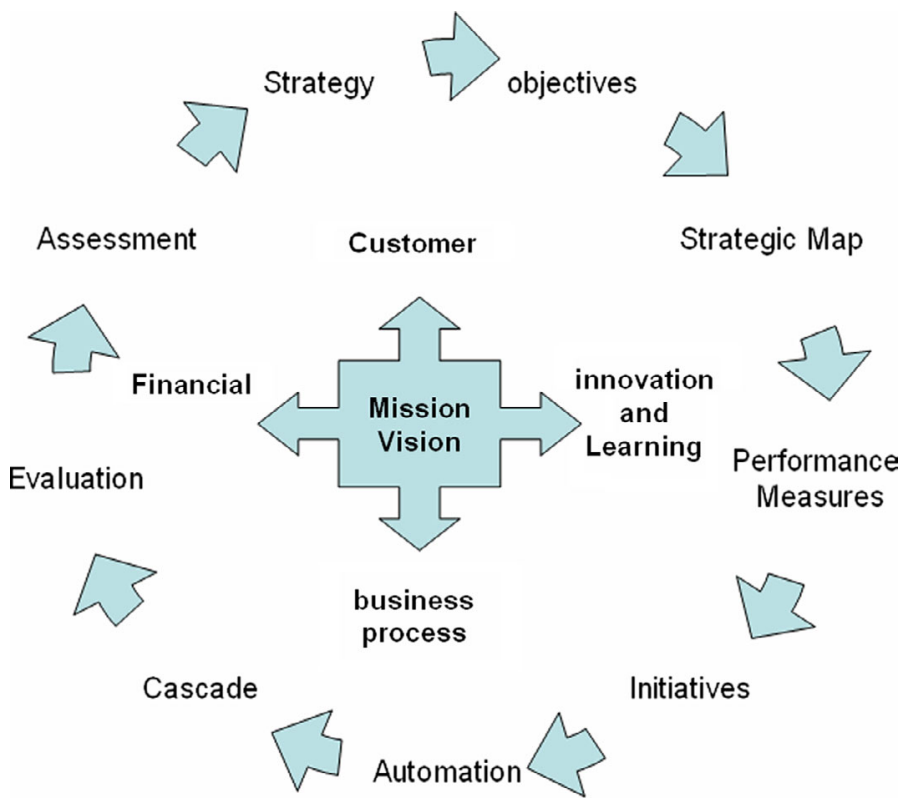

Figure 2. Process or steps of applying BSC 
BIJ

20,4

520

Elements of the organization's strategy, including strategic results, strategic themes and perspectives, are developed to focus attention on customer needs and the organization's value proposition. The organization translates its vision and mission through the development of strategic objectives aimed at achieving them.

The strategic elements developed in steps one and two are decomposed into strategic objectives, which are the basic building blocks of the strategy. Organization must determine the critical success factors that are compatible with the strategic goals and that the measurements are appropriate to measure the goals.

The cause and effect linkages between the enterprise-wide strategic objectives are formalized in an enterprise-wide strategy map. This is to clarify the causal relationships between different measurements and goals, so that there is coordination and a clear understanding of senior management vision.

Performance measures are developed for each of the enterprise-wide strategic objectives. Leading and lagging measures are identified, expected targets and thresholds are established and baseline and benchmarking data is developed. Designing BSC involves capturing the necessary information which are required for applying it for the system, and it includes objectives, targets and initiatives for all perspectives. Strategic initiatives are developed that support the strategic objectives.

The implementation process begins by applying performance measurement software to get the right performance information to the right people at the right time.

Cascading the scorecard level down into business and support unit scorecards is required. This means that the organizational level scorecard (the first tier) is translated into business unit or support unit scorecards (the second tier) and then later to team and individual scorecards (the third tier). This way, an evaluation of the completed scorecard is done.

\section{Applying BSC at Jordan E-Government}

The prime objective of the project on e-government in Jordan and the launch of e-government portal at the end of the year 2006 were to include the provision of e-government services in a number of departments and various government institutions to meet the needs of various sectors: citizens, business, and government. Typically, e-governments providing services to customers or users have several models, depending on the type of the dealings involved and these are categorised (Basu, 2004) as follows:

- government dealings with citizens (G2C);

- government dealings with the business sector and investors (G2B);

- business dealings with the government and investors (B2G);

- government transactions government (G2G); and

- dealings with government employees (G2E).

The main electronic services provided by Jordan E-Government include Services for Government Tenders, Services as prime minister, Income Tax Department, Customs Services, Services and the Ministry of Industry and Trade, National Information Technology Center, Lands and Survey, General Organization for Housing and Urban Development and Services of Greater Amman Municipality.

This research study investigates the BSC model we have developed for Jordan E-Government (Table I). This model has been adopted with an emphasis towards 


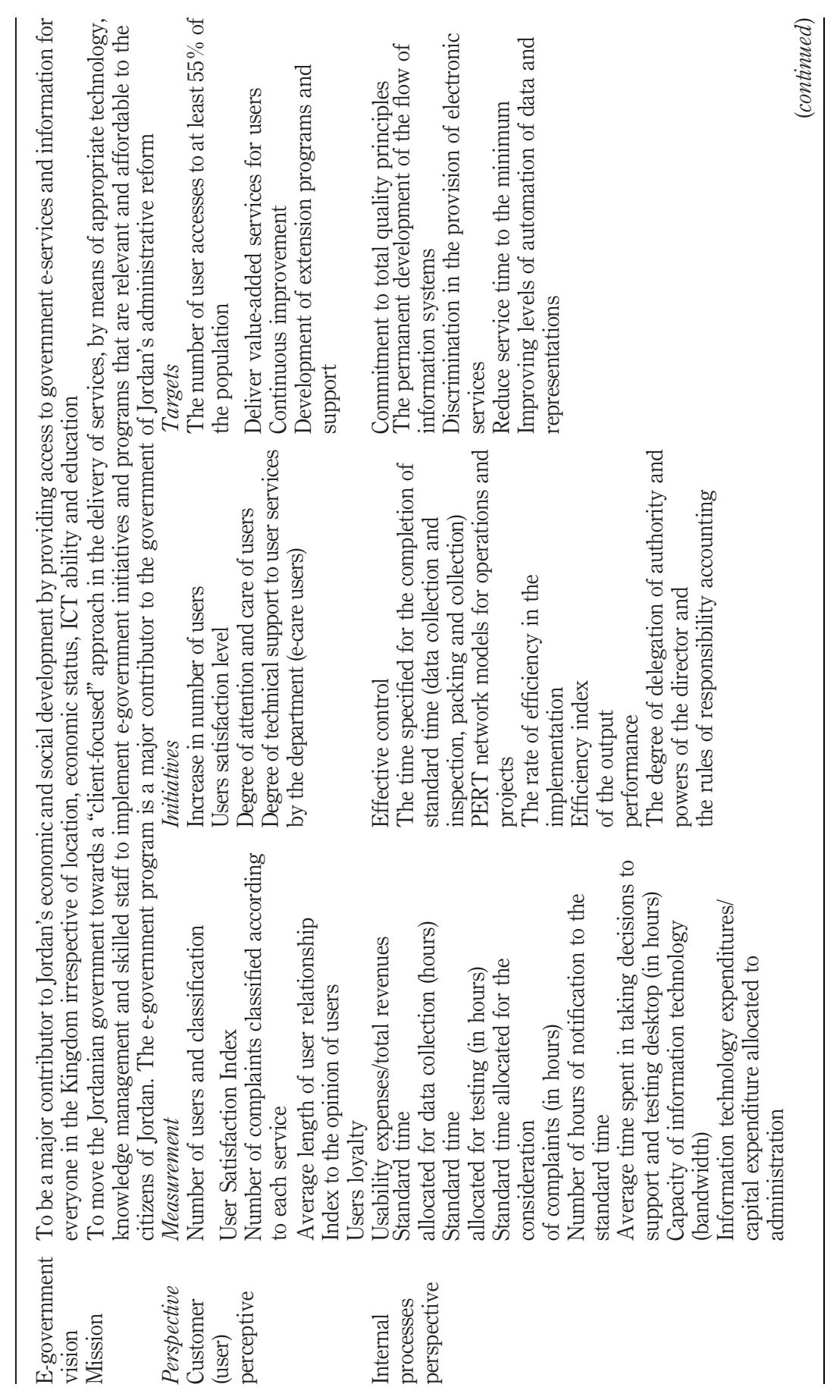

Evaluation of e-government services

521

Table I.

Jordan E-Government BSC model 
BIJ
20,4

522
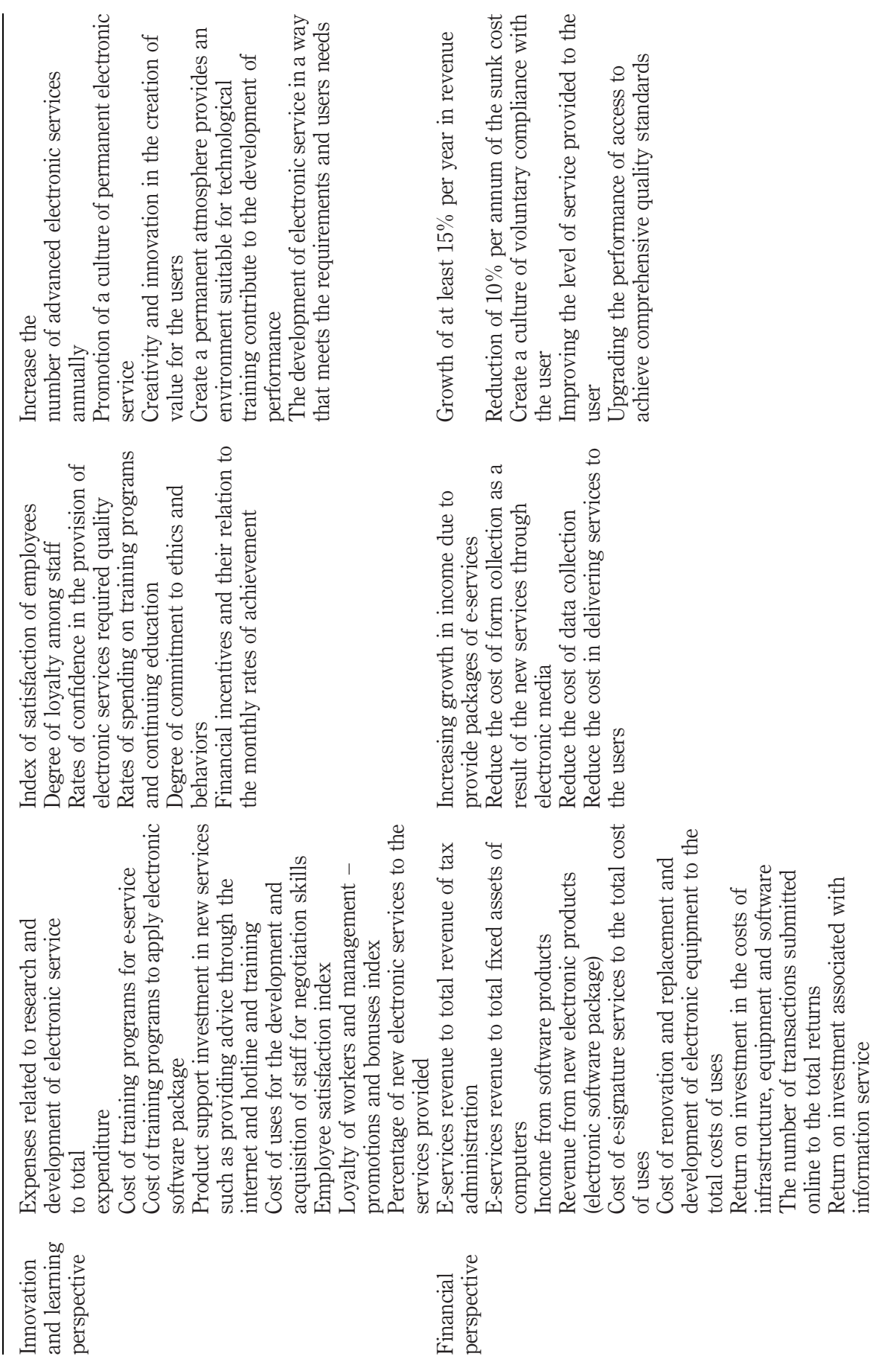

Table I. 
incorporating a suitable measurement system based on the insights gained from the literature review. We have allocated a total of 28 measurements and have distributed them among the four perspectives of BSC by incorporating the mission and vision developed by Jordan E-Government.

Research structure and hypothesis

Based on the reviewed literature, we have formulated the hypotheses of the model. Figure 3 shows an overview of the research model. The main hypothesis is divided into four sub-hypotheses to determine the effect of applying BSC in evaluating the e-government performance of Jordan, and these are given below:

Main hypothesis. There is no effect of applying BSC in evaluating the performance of e-government to maximize the return (the financial perspective, user perspective, internal processes perspective, and innovation and learning perspective).

We divide the main hypothesis into four sub-hypotheses as follows:

Sub-hypotheses (HO1). There is no statistical significant effect of applying the BSC in evaluating the performance of e-government to increase the return on e-government services.

Sub-hypotheses (HO2). There is no statistical significant effect of applying the BSC in evaluating the performance of e-government to increase user satisfaction.

Sub-hypotheses (HO3). There is no statistical significant effect of applying the BSC in evaluating the performance of e-government to increase efficiency and effectiveness.

Sub-hypotheses (HO4). There is no statistical significant effect of applying the BSC in evaluating the performance of e-government to increase skills of employees.

The design of the survey questionnaire used for testing the above hypotheses is described next.

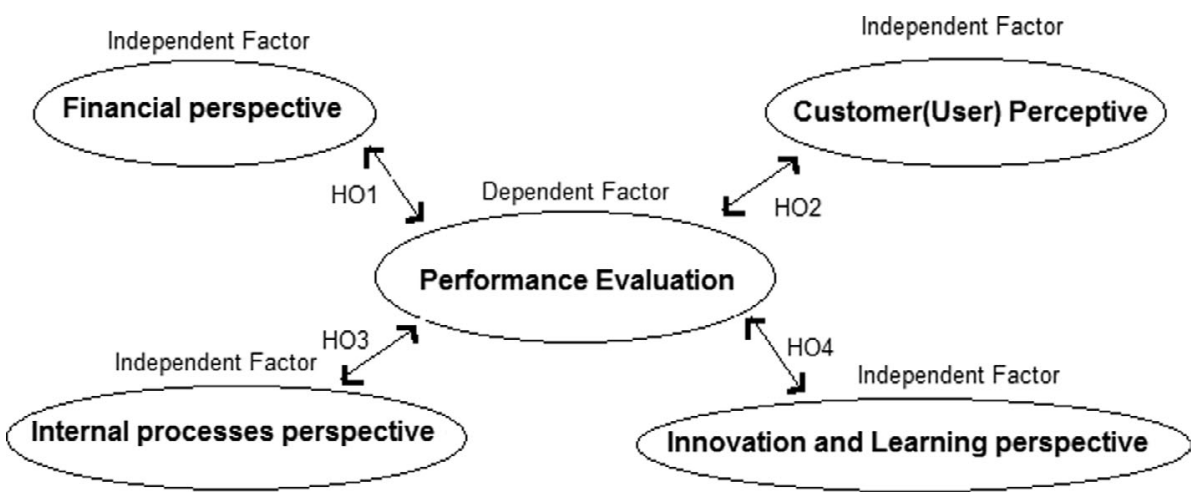

Evaluation of e-government services

523 
BIJ

20,4

524

Questionnaire design

The questionnaire consists of two main parts. Part I contains the user background and demographic information (e.g. gender, age, computing experience, interests in e-government/e-services). This was collected to conduct a demographic analysis in order to validate the authenticity and integrity of the data collected in Part II about effect of BSC in Jordan E-Government. Part II comprised of four main sections, each section comprising of questions involving BSC application in Jordan E-Government grouped under the financial perspective, customer perspective, internal process perspective and innovation and learning perspective. These form a one-to-one map with the four sub-hypothesis stated in the research model (Figure 3). The questions designed correspond to all the evaluation measures indicated in the Jordan E-Government BSC model shown in Table I. The items evaluated and measured through the questionnaire are also provided in Tables IV, VI, VIII and X. Apart from having a five-point Likert scale $(1$ - strongly agree down to 5 - strongly disagree) responses, additional comments were also collected from the participants. More details on the sampling and testing method used are explained next.

\section{Sampling and testing method}

The population for the study consists of employees in the e-government Unit at Ministry of Communications and Information Technology in Jordan, and group of customers (users) of e-government services. In additional to this, a group of employees from information technology and telecommunications sector in Jordan and researchers related to the field of e-government were included in the study population. The following Table II and Figure 4 show these details.

We have adopted survey research methodology as it is one of the main measurement methods widely accepted in social research. The survey method of data collection consists of two parts. The first part contains general information about the respondents such as, job title, interest, educational qualification, specialization, years of experience. The second part contains data of the study, and was divided into four lists of a questionnaire. Each list contains the terms provide a scale indicating the extent to which the viewpoint of respondents measure the contribution of each of the perspectives of BSC while assessing and evaluating the performance of e-government services. The data collected were analyzed using Statistical Package for Social Sciences (SPSS) software package to test the hypotheses.

To determine the impact of independent variables on dependent variables, we have adopted a quantitative research methodology in this study. We have used the Likert

Table II.

Groups of the study population

\begin{tabular}{|c|c|c|c|c|c|c|}
\hline \multirow{2}{*}{$\begin{array}{l}\text { Groups } \\
\text { Description }\end{array}$} & \multicolumn{2}{|c|}{$\begin{array}{l}\text { Questionnaires } \\
\text { distributed }\end{array}$} & \multirow{2}{*}{$\begin{array}{l}\text { Questionnaires } \\
\text { received } \\
\quad \text { No. }\end{array}$} & \multirow{2}{*}{$\begin{array}{l}\text { Questionnaires } \\
\text { excluded } \\
\text { No. }\end{array}$} & \multicolumn{2}{|c|}{$\begin{array}{l}\text { Questionnaires were } \\
\text { subject to analysis }\end{array}$} \\
\hline & No. & $\%$ & & & No. & $\%$ \\
\hline $\begin{array}{l}\text { Employees at } \\
\text { e-government }\end{array}$ & 100 & 21 & 82 & 11 & 71 & 18 \\
\hline Customers (users) & 280 & 60 & 264 & 16 & 248 & 6 \\
\hline $\begin{array}{l}\text { Employees at IT } \\
\text { sector }\end{array}$ & 50 & 11 & 34 & 3 & 31 & \\
\hline Researchers & 40 & 8 & 33 & 0 & 33 & \\
\hline Total & 470 & 100 & 413 & 30 & 383 & 100 \\
\hline
\end{tabular}




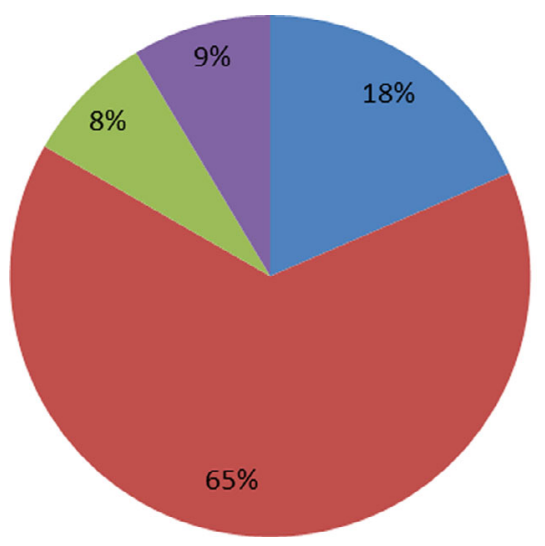

\section{Evaluation of e-government services}

Employees at e-Gov

$\square$ Customers (Users)

Employees at IT sector

Researchers (Jordan and Australia)

Figure 4.

Percentage of groups of the study population

five-scale for responses in the questionnaire, and the scale points are: 1 - strongly agree, 2 - agree, 3 - neutral, 4 - disagree, and, lastly, 5 - strongly disagree. We have followed the systematic sampling procedure given by Tabachnick and Fidell (2001) to arrive at a total of 383 participants for the survey and distributed the questionnaire to the study population. Part II was a questionnaire consisting of seven measurements designed with descriptive paragraphs and we distributed 71 questionnaires to the employees of e-government Unit at Ministry of Communications and Information Technology in Jordan.

The researchers used the SPSS software to conduct statistical analysis to prove or disprove hypotheses of this study. The testing was conducted with the objectives as follows:

(1) The descriptive statistics of the percentages, averages and standard deviations were used with respect to the study sample analysis, and the variables and dimensions of the study to determine the degree of importance of the measurements adopted.

(2) Ranking and level of assessment of the measurements are determined. A level of high is assigned if the value of the mean is 3.5 and above, Medium, if it lies in the range 3.0-3.49, and low less than 2.99. These are useful to understand the items of importance. Those that are at low or medium level require attention.

(3) One sample $t$-test: this test compares the calculated average with the standard of measure average of the Likert five-scale (null hypothesis at value 3 ) for testing the main hypothesis.

\section{Demographic analysis}

We had collected the general characteristics of the research sample, namely, educational qualification, years of experience; gender, job title, level using computer, specialization, interest, and the Table III shows the results.

We have noted from Table III, and Figure 5, that qualifications were mostly in the bachelor's degree and this is attributed to the fact that the tasks in e-government require a good level of education and learning to perform the job, while diploma holders and secondary education is limited to mainly data-entry task levels. In most sample cases, the number of years of experience is less than three years due to the recent launch of e-government services in Jordan, confirming the number of years of experience from 
BIJ

20,4

526

\begin{tabular}{|c|c|c|c|c|c|c|c|c|c|}
\hline \multirow[b]{2}{*}{ Variable } & \multirow{2}{*}{$\begin{array}{l}\text { Groups of the } \\
\text { variable }\end{array}$} & \multicolumn{2}{|c|}{$\begin{array}{l}\text { Employees } \\
\text { at e-gov. }\end{array}$} & \multicolumn{2}{|c|}{$\begin{array}{l}\text { Customers } \\
\text { (users) }\end{array}$} & \multicolumn{2}{|c|}{$\begin{array}{l}\text { Employees } \\
\text { at IT sector }\end{array}$} & \multicolumn{2}{|c|}{ Researchers } \\
\hline & & No. & $\%$ & No. & $\%$ & No. & $\%$ & No. & $\%$ \\
\hline \multirow{5}{*}{$\begin{array}{l}\text { Educational } \\
\text { qualification }\end{array}$} & High School & 14 & 19.72 & 59 & 23.79 & 1 & 3.23 & 0 & 0.00 \\
\hline & Diploma & 12 & 16.90 & 57 & 22.98 & 7 & 22.58 & 2 & 6.06 \\
\hline & Bachelors & 35 & 49.30 & 118 & 47.58 & 16 & 51.61 & 16 & 48.48 \\
\hline & Master & 8 & 11.27 & 8 & 3.23 & 6 & 19.35 & 9 & 27.27 \\
\hline & PHD & 2 & 2.82 & 6 & 2.42 & 1 & 3.23 & 6 & 18.18 \\
\hline \multirow[t]{4}{*}{ Years of experience } & $\begin{array}{l}\text { Less than three } \\
\text { years }\end{array}$ & 25 & 35.21 & 149 & 60.08 & 11 & 35.48 & 25 & 75.76 \\
\hline & $\begin{array}{l}\text { From three to } \\
\text { six years }\end{array}$ & 17 & 23.94 & 25 & 10.08 & 9 & 29.03 & 6 & 18.18 \\
\hline & $\begin{array}{l}\text { From eight to } \\
\text { ten years }\end{array}$ & 15 & 21.13 & 40 & 16.13 & 7 & 22.58 & 1 & 3.03 \\
\hline & $\begin{array}{l}\text { More than } \\
\text { en years }\end{array}$ & 14 & 19.72 & 34 & 13.71 & 4 & 12.90 & 1 & 3.03 \\
\hline \multirow[t]{2}{*}{ Gender } & Male & 45 & 63.38 & 125 & 50.40 & 23 & 74.19 & 23 & 69.70 \\
\hline & Female & 26 & 36.62 & 123 & 49.60 & 8 & 25.81 & 10 & 30.30 \\
\hline \multirow[t]{2}{*}{ Job title } & Technical support & 63 & 88.73 & - & - & - & - & - & - \\
\hline & Administrative & 8 & 11.27 & - & - & - & - & - & - \\
\hline \multirow[t]{3}{*}{ Level using computer } & Professional & - & - & 91 & 36.69 & - & - & - & - \\
\hline & Very good & - & - & 96 & 38.71 & - & - & - & - \\
\hline & Good & - & - & 61 & 24.60 & - & - & - & - \\
\hline \multirow[t]{3}{*}{ Specialization } & Computer Science & - & - & - & - & 11 & 35.48 & - & - \\
\hline & Network & - & - & - & - & 4 & 12.90 & - & - \\
\hline & $\begin{array}{l}\text { Software and } \\
\text { hardware }\end{array}$ & - & - & - & - & 16 & 51.61 & - & - \\
\hline \multirow[t]{2}{*}{ Interest } & E-government & - & - & - & - & - & - & 29 & 87.88 \\
\hline & E-services & - & - & - & - & - & - & 4 & 12.12 \\
\hline Total & & 71 & & 248 & & 31 & & 33 & \\
\hline
\end{tabular}

Figure 5.

The characteristics of the research sample

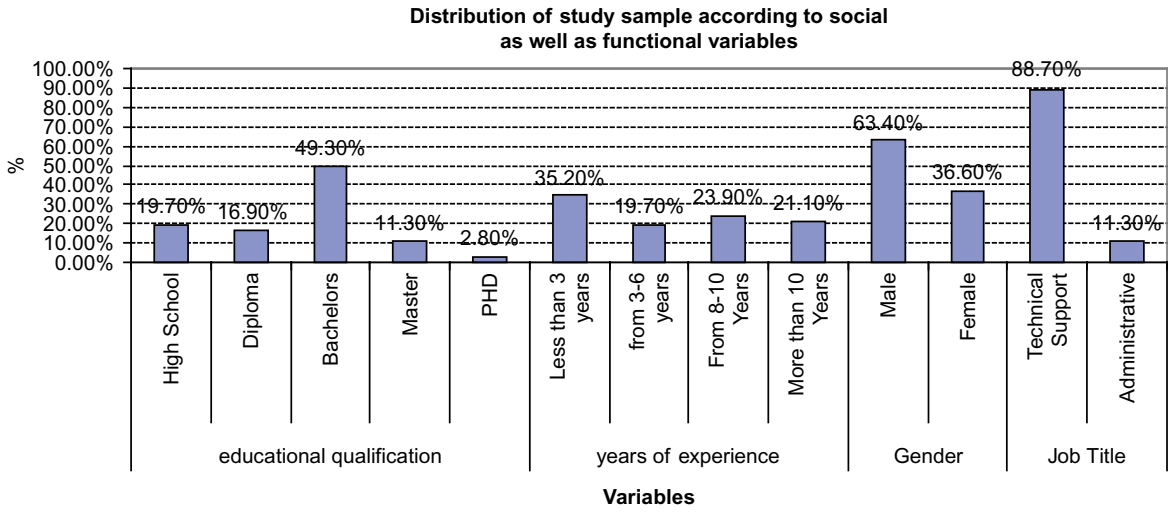

Note: Employees in the e-government unit at ministry of communications and information technology - Jordan 
most members of the study sample being their first job. Also, most of the job title for the study sample was technical support, as this was assigned target in the study sample. These general characteristics form means of validating the integrity of the data collected from the study sample.

With descriptive paragraphs at the customers perspective (users of e-government services in Jordan). The researchers were distributed to 248 Table III and Figure 6 show the general characteristics of the research sample (educational qualification, years of experience, gender, level of using computer) and the statistical results obtained.

We observe from Table III that the gender of population study indicates male as 50.4 percent and female as 49.6 percent. This refers to the gender equality of members of the research sample that serves one of the objectives of the study, namely, to know the views of both genders. Also, 60.08 percent of the population indicates less than three experiences dealing with e-government services and this attributes to the recent awareness of the importance of using e-government services. In terms of level of using computers, we observe that the population was being in very good level of computer literacy, as 96 respondents have indicated very good level of using computer, and also the population being educated, possessing the ability to use computers for e-service provided by Jordan E-Government.

Also we observe from Table III similar characteristics of the population sample as in previous cases at the group of employees in information technology and telecommunications sector, in additional to that we observe that the population study had specialization in several majors in information and telecommunication technology. We have aimed to target these specializations to serve the objective of the study, namely to measure the efficiency and effectiveness from internal processes perspective, and Figure 7 shows the result.

In additional to the group of researchers related to the field of e-government we observe that the population study has interest in e-government field. We aimed to target this characteristic in the population sample to serve the objective of the study, namely to measure the increasing skills of employees, and Figure 8 shows the result.

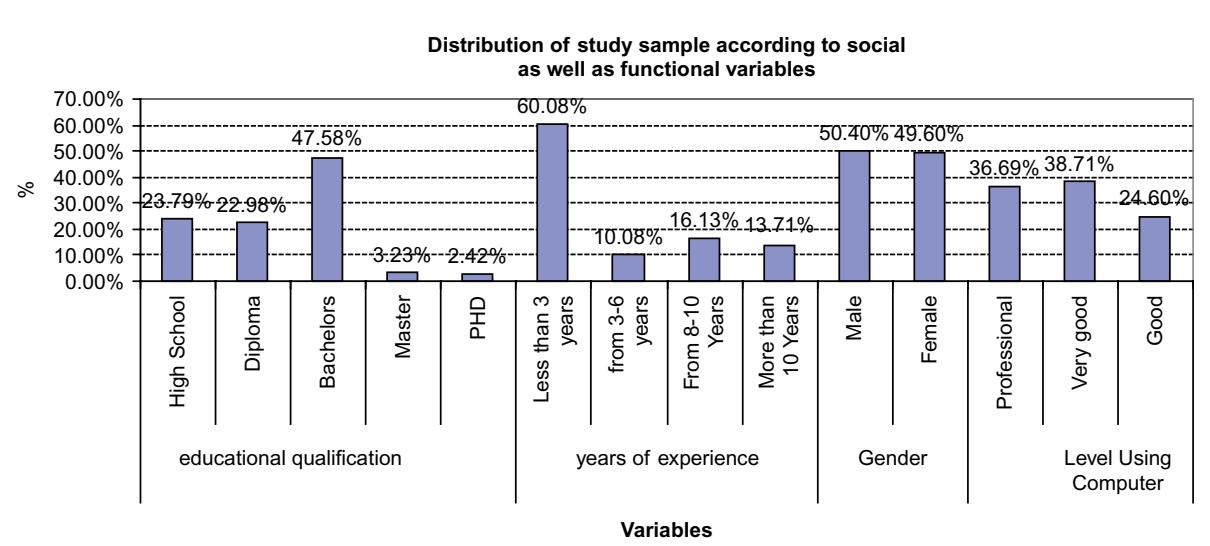

Note: Group of customers of e-government services - Jordan
Evaluation of

e-government services

527
Figure 6.

The characteristics of the research sample 
BIJ

20,4

\section{8}

Figure 7.

The characteristics of the research sample

Figure 8.

The characteristics of the research sample

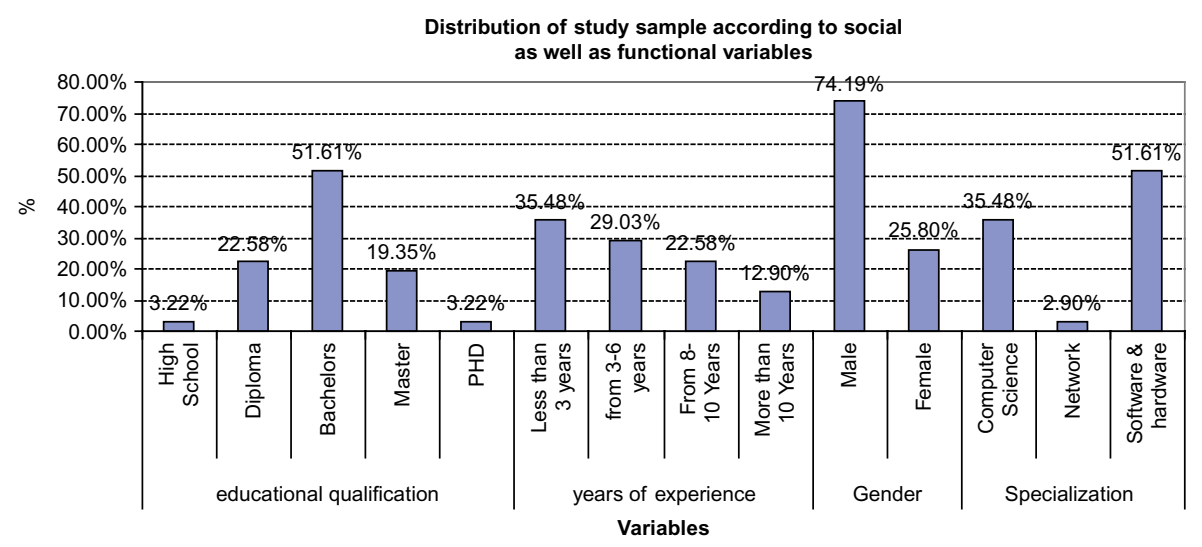

Note: Group of employees in information technology and telecommunications sector

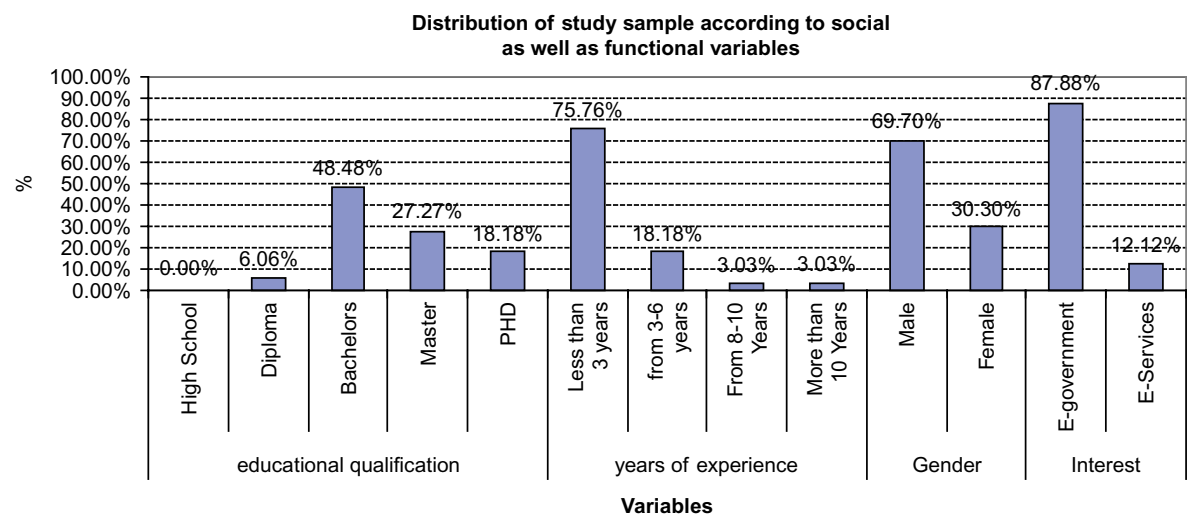

Note: Group of researchers related to the field of e-government

\section{Hypotheses testing results and analysis}

We had collected data of the survey questionnaire to test the first sub-hypothesis (there is no statistical significant effect of applying the BSC in evaluating the performance of e-government to increase the return on e-government services) based on (finance perspective) that was designed with inputs from literature and it comprised of two parts. Part I was dedicated to gathering general data on the study sample.

The calculated averages and standard deviations were reached for the study and based on the established standards that, if the value of the mean of the parameter in each paragraph of the questionnaire was more than 3.5 the level of assessment of the measurements is considered as high, if the value of the mean lies in the range 3.0-3.49, the level of assessment of subjects is considered as medium, and if the averages is less than 2.99, the level of assessment of subjects is considered as low. Table IV shows these statistical results. 


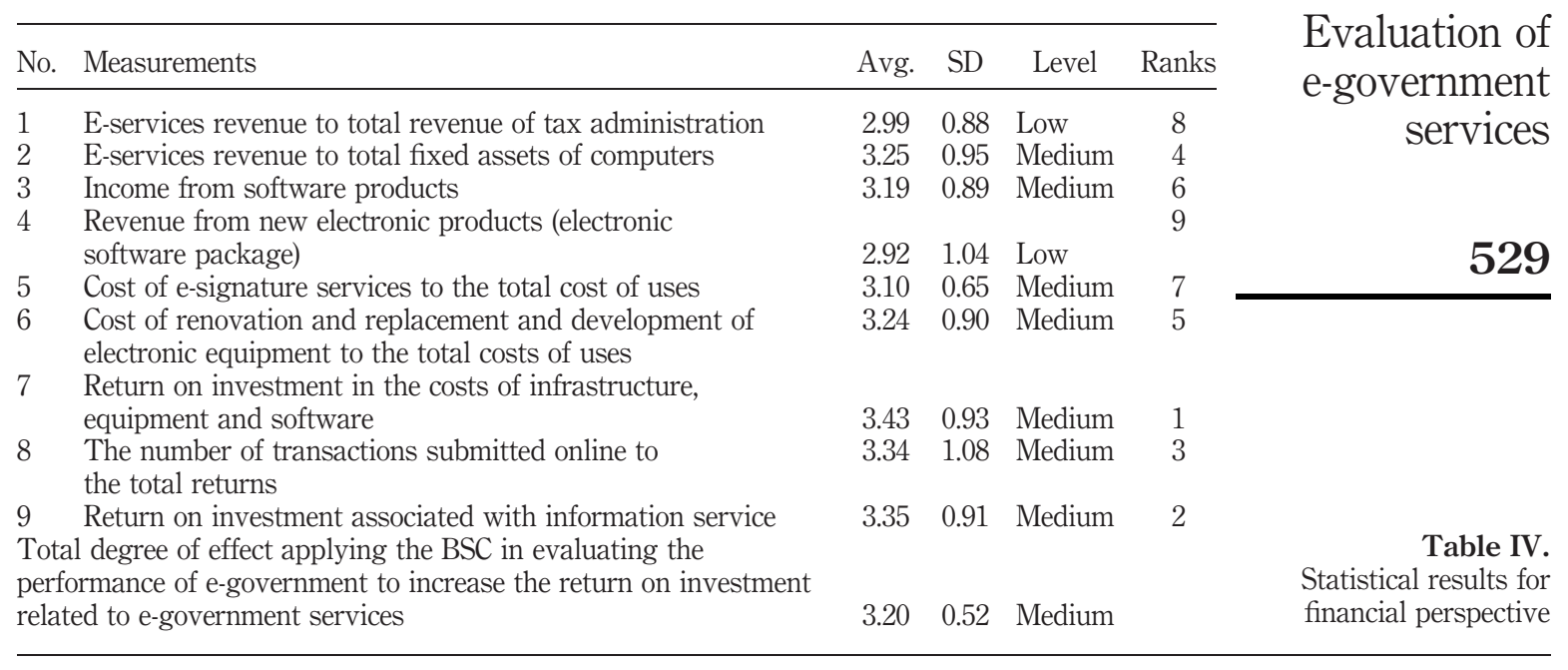

From Table IV, it is observed that there is significant effect of applying the BSC in evaluating the performance of e-government to increase the return on e-government services as the overall measure is medium (3.20). The paragraphs $2,3,5,6,7,8$, and 9 show medium effect, while the paragraph 1 and 4 indicates low effect. The table also points out the importance of measurements, where the seventh measurement (return on investment in the costs of infrastructure, equipment and software) is the highest value with average of 3.43 , which refers to the degree of importance given to this measure. Also, the revenue from new electronic products (electronic software package) is observed to be of lowest rank or low degree of importance measure, with average of 2.92. We have ranked all the measurements according to the degree of importance conceived by the respondents.

To test the validity of first sub-hypotheses (HO1), we have employed $t$-test on the sample and we observe from the Table $\mathrm{V}$ that the value of $t$ is equal to 6.11, and the value of probability (0.00) is less than the significance level $(\alpha=0.05)$, indicating the rejection of the hypothesis. This means that there is statistical significant effect of applying the BSC in evaluating the performance of e-government to increase the return on e-government services.

Next, we had collected data by means of a survey questionnaire to test the second sub-hypothesis: there is no statistical significant effect of applying the BSC in evaluating the performance of e-government to increase user satisfaction. A questionnaire consisting of six measurements (based on customers' or users' perspective) was designed.

Similar to the first hypothesis, we have calculated averages and standard deviations for the second hypothesis, Table VI provides the statistical results obtained.

\begin{tabular}{lcccc}
\hline Mean & df. & Test value $=3$ & & \\
\hline 3.20 & 70 & & $t$ & Sig. \\
\hline
\end{tabular}

Note: *Statistically significant at the level of significance $(\alpha=0.05)$

Table V.

Results of test first hypothesis ( $t$-test sample) 
BIJ

20,4

530

We observe from Table VII that there is significant effect of applying the BSC in evaluating the performance of e-government to increase users' satisfaction, where the total degree is observed to be medium (3.11). The paragraphs 1,2 , and 3 shows high effect for these measurements, while the paragraphs 4 and 5 indicate medium effect, and last paragraph exhibits low effect. The table also points out the importance of measurements, where the first measurement (number of users and classification) has high average (3.54) which refers to degree of importance of this measure. Also, Users Satisfaction Index has high average or degree of importance measure with an average of 3.52. We have ranked all the measurements according to the degree of importance conceived by the respondents.

To test the validity of second sub-hypotheses (HO2), we have employed $t$-test on the sample and we observe from the Table VII that the value of $t$ is equal to 5.29 , and the value of probability (0.00) is less than the significance level $(\alpha=0.05)$, indicating the rejection of the hypothesis. That means that there is statistically significant effect of applying the BSC in evaluating the performance of e-government to increase user's satisfaction.

Next, we had collected data by means of a survey questionnaire to test the third sub-hypothesis: there is no statistical significant effect of applying the BSC in evaluating the performance of e-government to increase efficiency and effectiveness. A questionnaire consisting of eight measurements (based on Internal processes perspective) was designed with descriptive paragraphs and was distributed to 31 employees in information technology and telecommunications sector in Jordan. Table VIII provides the statistical results obtained (Table IX).

We observe from Table X that there is significant effect of applying the BSC in evaluating the performance of e-government to increase the efficiency and effectiveness, with the total degree calculated as high (3.92). The paragraphs 2-8 shows high effect for these measurements, while the first paragraph indicates medium effect. The table also points out the importance of these measurements, where the third measurement (standard time allocated for testing) has a high average of 4.28 , which refers to the degree

Table VI.

Statistical results for customer perspective

\begin{tabular}{llcclc}
\hline No. & Measurements & Avg. & SD & Level & Ranks \\
\hline 1 & Number of users and classification & 3.54 & 0.88 & High & 1 \\
2 & Users Satisfaction Index & 3.52 & 1.04 & High & 2 \\
3 & Number of complaints are classified according to each service & 3.51 & 1.19 & High & 3 \\
4 & 3.17 & 1.29 & Medium & 4 \\
5 & Average length of user relationship & 3.14 & 1.23 & Medium & 5 \\
$6 \quad$ User to the opinion of users & 2.92 & 0.49 & Low & 6 \\
Total degree of effect for applying the BSC in evaluating the & & & & \\
performance of e-government to increase users' satisfaction & 3.11 & 0.60 & Medium & \\
\end{tabular}

Table VII.

Results of test second hypothesis ( $t$-test sample)

\begin{tabular}{lcccc}
\hline Mean & df. & Test value $=3$ & & \\
\hline 3.11 & 247 & & 5.29 & Sig. \\
\hline
\end{tabular}

Note: *Statistically significant at the level of significance $(\alpha=0.05)$ 


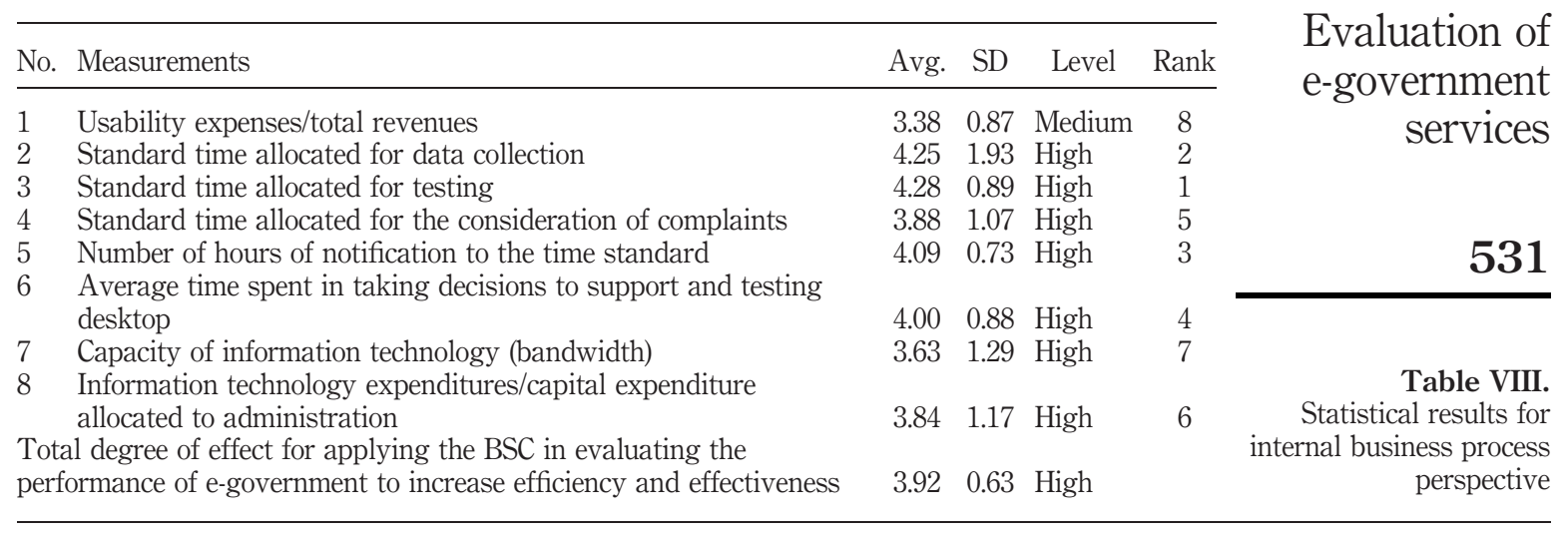

\begin{tabular}{lcccc}
\hline Mean & df. & Test value $=3$ & & Sig. \\
3.92 & 30 & 14.94 & 0.00 & $\begin{array}{r}\text { Table IX. } \\
\text { Results of test third } \\
\text { Note: *Statistically significant at the level of significance }(\alpha=0.05)\end{array}$ \\
\hline
\end{tabular}

\begin{tabular}{|c|c|c|c|c|c|c|}
\hline No. & Measurements & Avg. & $\mathrm{SD}$ & Level & Rank & \\
\hline 1 & $\begin{array}{l}\text { Expenses related to research and development of electronic service } \\
\text { to total expenditure }\end{array}$ & 3.10 & 0.65 & Medium & 6 & \\
\hline 2 & Cost of training programs for e-service & 3.24 & 0.90 & Medium & 4 & \\
\hline 3 & $\begin{array}{l}\text { Cost of training programs on the application of electronic software } \\
\text { package }\end{array}$ & 3.43 & 0.93 & Medium & 1 & \\
\hline 4 & $\begin{array}{l}\text { Product support investment in new services such as providing } \\
\text { advice through the internet and hotline and training }\end{array}$ & 3.34 & 1.08 & Medium & 2 & \\
\hline 5 & $\begin{array}{l}\text { Cost of uses for the development and acquisition of staff for } \\
\text { negotiation skills }\end{array}$ & 2.99 & 0.88 & Medium & 7 & \\
\hline 6 & Employees satisfaction index & 3.25 & 0.95 & Medium & 3 & \\
\hline 7 & $\begin{array}{l}\text { Loyalty of workers and management - promotions and bonuses } \\
\text { index }\end{array}$ & 3.19 & 0.89 & Medium & 5 & Table X. \\
\hline $\begin{array}{l}8 \\
\text { Tota } \\
\text { perfo }\end{array}$ & $\begin{array}{l}\text { Percentage of new electronic services to the services provided } \\
\text { al degree of effect for applying the BSC in evaluating the } \\
\text { ormance of e-government to increase skills of employees }\end{array}$ & $\begin{array}{l}2.92 \\
3.19\end{array}$ & 1.04 & Medium & 8 & $\begin{array}{r}\text { Statistical results for } \\
\text { innovation and learning } \\
\text { perspective }\end{array}$ \\
\hline
\end{tabular}

of importance of this measure. Also, standard time allocated for data collection has a high average or degree of importance measure, with an average of 4.25. As before, we have ranked all the measurements according to the degree of importance conceived by the respondents.

To test the validity of third sub-hypotheses (HO3), we have employed $t$-test on the sample and we observe from the Table XI that the value of $t$ is equal to 14.94, and the value of probability $(0.00)$ is less than the significance level $(\alpha=0.05)$, indicating 
BIJ

20,4

532

the rejection of the hypothesis. That means that there is statistically significant effect of applying the BSC in evaluating the performance of e-government to increase efficiency and effectiveness at internal processes.

Next, we had collected data by means of a survey questionnaire to test the fourth sub-hypothesis: there is no statistical significant effect of applying the BSC in evaluating the performance of e-government to increase skills of employees. A questionnaire consisting of eight measurements (based on innovation and learning perspective) was designed with descriptive paragraphs and was distributed to 33 employees in e-government and a group of researchers related to the field of e-government. Apart from researchers in Jordan, some researchers who are Jordan citizens living in Australia were also included to participate in the study so as to understand how they are able to make use of the Jordanian E-Government services remotely and view them as compared to those e-government services designed in other developed countries.

Similar to the previous hypotheses, we have calculated averages and standard deviations for the fourth hypothesis. Table X provides the statistical results obtained.

We observe from Table XI that there is significant effect of applying the BSC in evaluating the performance of e-government to increase the skills of employees, with the total degree calculated as medium (3.21). All the eight paragraphs show medium effect for these measurements, and the third paragraph (the cost of training programs on the application of electronic software package) indicates almost high (3.43) effect. Also, product support investment in new services such as providing advice internet and hotline and training has almost high average or degree of importance measure, with an average of 3.34. As before, we have ranked all the measurements according to the degree of importance conceived by the respondents.

To test the validity of fourth sub-hypotheses (HO4), we have employed $t$-test on the sample and we observe from the Table XI that the value of $t$ is equal to 6.11, and the value of probability (0.00) is less than the significance level $(\alpha=0.05)$, indicating the rejection of the hypothesis. That means that there is statistically significant effect of applying the BSC in evaluating the performance of e-government to increase skills of employees at Innovation and Learning perspective.

According to testing the four sub-hypotheses that pointed the degree of importance for all measurements, the rejection of all four sub-hypotheses has led to reject main hypothesis: "there is no effect of applying of BSC in evaluating the performance of e-government to maximize the return (the financial perspective, user perspective, internal processes perspective and Innovation and Learning perspective)". This means that by applying BSC in evaluating the performance of e-government, it will perform to maximize the return for all perspectives of BSC. Hence, we have achieved the purpose of the study in investigating and verifying the importance of using BSC approach in e-government to evaluate and measure its performance.

Table XI.

Results of test fourth hypothesis ( $t$-test sample)

\begin{tabular}{llccc}
\hline Mean & df. & Test value $=3$ & $t$ & Sig. \\
\hline 3.19 & 32 & & 6.11 & 0.00
\end{tabular}

Note: *Statistically significant at the level of significance $(\alpha=0.05)$ 


\section{Conclusions}

The empirical study conducted in this research work reveals the need to use the BSC framework in assessing and evaluating the performance of e-government and measuring the performance of e-service delivery. The testing of hypotheses clearly suggests that applying BSC has maximized the return on investment of such services in Jordan E-Government. Among the four perspectives of the BSC, the maximum positive effect was attributed to internal business process and following this is the financial perspective. However, customer perspective has received least effect. The feedback through comments collected through the questionnaire of the study has identified the need to provide user training programs to encourage interactions with such services electronically with a view to keep pace with global development in preserving the green environment. There is also a strong desire and motivation to use mobile devices in all government services and transactions.

The innovation and learning perspective shows the next least effect indicating that continuous attention has to be given towards employees' development and to activate rewards and promotions systems that would lead to their advancement and growth. Motivation among workers should be uplifted and in order to elevate the degree of belonging to the organization and their job satisfaction and these require to be measured from time to time.

Overall, we conclude that by applying the BSC framework in evaluating the performance of e-government, the efficiency and effectiveness of internal processes have improved, and this would have an important role in raising the measurements of the other three perspectives in the long-term.

\section{References}

Ababneh, R. (2008), "A comprehensive performance evaluation of the Jordanian customs department using the balanced scorecard", Jordan Journal of Business Administration, Vol. 4 No. 4, pp. 463-484.

Alkhaleefah, M., Alkhawaldeh, M., Venkatraman, S. and Alazab, M. (2010), "Towards understanding and improving e-government strategies in Jordan”, International Conference on E-Commerce, E-Business and E-Service, World Academy of Science, Engineering and Technology, No. 66, pp. 1871-1877.

Basu, S. (2004), "E-government and developing countries: an overview", International Review of Law Computers and Technology, Vol. 18 No. 1, pp. 109-132.

Bourne, M., Neely, A., Mils, J. and Platts, K. (2003), "Implementing performance measurement systems: a literature review", International Journal of Business Performance Management, Vol. 5 No. 1, pp. 1-24.

Brown, M. (2007), Beyond the Balanced Scorecard: Improving Business Intelligence with Analytic, Vol. 24 No. 11, Productivity Press, New York, NY.

Cameron, K.S. and Whetten, D.A. (1983), Organisational Effectiveness: A Comparison of Multiple Models, Academic Press, New York, NY.

Castelnovo, W. and Simonetta, M. (2007), "The evaluation of e-government projects for small local government organizations", The Electronic Journal of E-Government, Vol. 5 No. 1, pp. 21-28.

Corradini, F., Polzonetti, A., Barbara, R. and Tesei, L. (2008), "Quality of service in e-government underlines the role of information usability", International Journal of Information Quality, Vol. 2 No. 2, pp. 133-151.

\section{Evaluation of \\ e-government \\ services}

533 
BIJ

20,4

534
Dixon, J.R., Nanni, A.J. and Vollmann, T.E. (1990), The New Performance Challenge: Measuring Operations for World-Class Competition, Dow Jones-Irwin, Homewood, IL.

Ellingson, D.A. and Wambsganss, J.R. (2001), "Modifying the approach to planning and evaluation in governmental entities: a balanced scorecard approach", Journal of Public Budgeting, Accounting \& Financial Management, Vol. 13 No. 1, pp. 103-120.

Fountain, J.E. (2001), Building the Virtual State: Information Technology and Institutional Change, Brookings Institution Press, Washington, DC.

Greunz, M., Schopp, B. and Haes, J. (2001), "Integrating e-government infrastructure through secure XML document containers", Proceedings of the 34th Annual Hawaii International Conference on System Sciences, Maui, Hawai, pp. 1-10.

Gunasekaran, A. and Kobu, B. (2007), "Performance measures and metrics in logistics and supply chain management: a review of recent literature (1995-2004) for research and applications", International Journal of Production Research, Vol. 45 No. 12, pp. 2819-2840.

Gupta, M.P. and Jana, D. (2003), "E-government evaluation: a framework and case study", Government Information Quarterly, Vol. 20, pp. 365-387.

Horngren, C., Foster, G., Datar, S., Rajan, M. and Ittner, C. (2000), Cost Accounting: A Managerial Emphasis, Prentice-Hall, Englewood Cliffs, NJ.

Inamdar, N., Kaplan, R. and Reynolds, K. (2002), "Applying the balanced scorecard fin healthcare provider organization/practitioner response”, Journal of healthcare Management, Vol. 47 No. 3, pp. 179-196.

Jeanes, C. (1996), "Customer satisfaction and business results: is there a link?”, Customer Service Management, March, pp. 46-48.

Johnson, H.T. (1981), "Towards a new understanding of nineteenth-century cost accounting", The Accounting Review, Vol. 56 No. 3, pp. 510-518.

Judeh, M.A. (2008), "The implementation of the balanced scorecard and its effect on the organizational commitment of the employees of Jordanian aluminum companies: a field stud", Jordan Journal of Applied Science: Humanities Series, Vol. 11 No. 2, pp. 273-292.

Jyoti, D.K.B. and Deshmukh, S.G. (2008), "Evaluating performance of national R\&D organizations using integrated DEA-AHP technique", International Journal of Productivity and Performance Management, Vol. 57 No. 5, pp. 370-388.

Kaplan, R.S. (1994), "Devising a balanced scorecard matched to business strategy", Strategy \& Leadership, Vol. 22 No. 5, pp. 15-48.

Kaplan, R.S. (2010), Conceptual Foundations of the Balanced Scorecard, Harvard Business School, Harvard University, Allston, MA, (Paper originally prepared for Chapman, A., Hopwood, G.H., Chapman, S.C. and Shields, M.D. (2009), Handbook of Management Accounting Research, Vol. 3, Elsevier Science Title).

Kaplan, R.S. and Anthony, A.A. (1998), Advanced Management Accounting, Prentice-Hall, Upper Saddle River, NJ.

Kaplan, R.S. and Norton, D.P. (1992), "The balanced scorecard measures that drive performance", Harvard Business Review, Vol. 70 No. 1, pp. 71-79.

Kaplan, R.S. and Norton, D.P. (1993), "Putting the balanced scorecard to work", Harvard Business Review, September/October, pp. 134-147.

Kaplan, S.R. and Norton, D.P. (1996), "Using the balanced scorecard as a strategic management system”, Harvard Business Review, Vol. 74 No. 1, pp. 75-85. 
Klecun, E. and Cornford, T. (2005), “A critical approach to evaluation”, European Journal of Information Systems., Vol. 14 No. 3, pp. 229-243.

Maiga, A. and Jacobs, F. (2003), "Balanced scorecard, activity-based costing and company performance: an empirical analysis", Journal of Management Issues, Vol. 15 No. 3, pp. 283-301.

Neely, A.D. (1998), Measuring Business Performance: Why, What and How, The Economist Books, London.

Neely, A.D., Mills, J.F., Gregory, M.J. and Platts, K.W. (1995), "Performance measurement system design - a literature review and research agenda", International Journal of Operations and Production Management, Vol. 15 No. 4, pp. 80-116.

Neely, A.D., Mills, J.F., Gregory, M.J. and Richards, A.H. (1996a), Getting the Measure of Your Business, Findlay, London.

Neely, A., Mills, J., Platts, K., Gregory, M. and Richards, H. (1996b), "Performance measurement system design: should process based approaches be adopted?", International Journal of Production Economics, Vol. 46/47 No. 1, pp. 423-431.

Niven, P.R. (2003), Balanced Scorecard Step-by-Step for Government and Nonprofit Agencies, Wiley, Hoboken, NJ.

Punniyamoorthy, M. and Murali, R. (2008), "Balanced score for the balanced scorecard: a benchmarking tool", Benchmarking: An International Journal, Vol. 15 No. 4, pp. $420-443$.

Rohm, H. (2002), Improve Public Sector Results with a Balanced Scorecard: Nine Steps to Success, Vol. 3 No. 2, US Foundation for Performance Measurement, Raleigh, NC.

Sedera, D., Gable, G. and Rosemann, M. (2001), "A balanced scorecard approach to enterprise systems performance measurement", Proceedings of the Twelfth Australasian Conference on Information Systems, In Harbour, Coffs \& South Wales.

Sharma, A. (2009), "Implementing balanced scorecard for performance measurement", ICFAI Journal of Business Strategy, Vol. 6 No. 1, pp. 7-16.

Srinivasan, R. and Iyappan, G.I. (2009), "Different methodologies and methods of e-governance using open source technology”, Emerging Technologies in E-Government, June, pp. 133-141.

Stowers, G.N.L. (2004), Issues in E-Commerce and E-Government Service Delivery, Digital Government, IGI Publishing, Hershey, PA, pp. 169-185.

Tabachnick, B.G. and Fidell, L.S. (2001), Using Multivariate Statistics, 4th ed., Allyn \& Bacon, Needham Heights, MA.

Thorp, J. (1999), "The information paradox: realizing the business benefits of information technology", paper presented at Symposium on IT Balanced Scorecard, Antwerp, March.

UN Report (2006), "Developing e-government indicators", paper presented at Annual Meeting of the African Technical Advisory Committee, United Nations Conference Center, 12-14 December, Economic Commission for Africa, Addis Ababa, Ethiopia.

Walsham, G. (1999), "Interpretive evaluation design for information systems", in Willcocks, L.P. and Lester, S. (Eds), Beyond the It Productivity Paradox, Wiley, Chichester, pp. 363-380.

Werner, M.L. and Xu, F. (2011), "Successfully executing strategy by implementing the balanced scorecard", Proceedings of 2011 International Conference on Computer and Management, Wuhan, 27 May, pp. 1-5.

West, D.M. (2000), Assessing E-Government: The Internet, Democracy, and Service Delivery by State and Federal Governments, Brown University, Providence, RI.

\section{Evaluation of e-government services} (1) 
BIJ

20,4

536
Wright, W., Smith, R., Jesser, R. and Stupeck, M. (1999), "Information technology, process reengineering and performance measurement: a balanced scorecard analysis of Compaq computer corporation”, Communications of the Association for Information Systems, Vol. 8 No. 1, pp. 1-47.

Ying, J. (2010), “The application of BSC in China's e-government performance evaluation”, Symposium on Reform and Transition in Public Administration Theory and Practice in Greater China, pp. 1-4.

Yu, L., Perera, S. and Crowe, S. (2008), "Effectiveness of the balanced scorecard: the impact of strategy and causal links", Journal of Applied Management Accounting Research, Vol. 6 No. 2, pp. 37-56.

\section{Corresponding author}

Sitalakshmi Venkatraman can be contacted at: sita.venkat@gmail.com 